\title{
Morphophonological influences on the construction of subject-verb agreement
}

\author{
ROBERT J. HARTSUIKER \\ Ghent University, Ghent, Belgium \\ HERBERT J. SCHRIEFERS \\ Nijmegen Institute for Cognition and Information, Nijmegen, The Netherlands \\ KATHRYN BOCK \\ University of Illinois at Urbana-Champaign, Champaign, Illinois \\ and \\ GERDIEN M. KIKSTRA \\ Nijmegen Institute for Cognition and Information, Nijmegen, The Netherlands
}

\begin{abstract}
In three experiments, we investigated whether the production of subject-verb number agreement is affected by the phonological realization of grammaticalinformation. Speakers repeated and completed German or Dutch noun phrases along the lines of The position against the demonstrations. We varied the number of the subject noun (position) and the local noun (demonstrations), as well as the number ambiguity of the subject noun's determiner and the case ambiguity of the local noun phrase. Sentence completions more often contained a verb of the wrong number if the subject and the local nouns mismatched in number than if they matched. Experiments 1 and 2, in German, showed a stronger number mismatch effect if the local noun phrase was ambiguous between the nominative and the accusative cases. Experiment 3, in Dutch, showed a stronger mismatch effect if the subject noun's determiner was ambiguous in number. We conclude that morphophonological factors affect the implementation of agreement during grammatical encoding.
\end{abstract}

Many theorists of language production conceive there to be a number of levels that mediate the translation between meaning and sound. Levelt (1989) distinguished the processes of conceptualizing (constructing a preverbal message based on one's intentions, beliefs, knowledge, and current discourse model), formulating (creating a hierarchically and serially organized sentence structure that contains the words, including their phonological properties and prosodic form), and articulating (coordinating the speech motor system and executing the appropriate motor commands). Formulating is further divided into grammatical encoding (selection of words and construction of structure) and phonological encoding (determining the segmental and metrical properties of words in connected speech). Levelt (1989; see also Bock \& Levelt, 1994; Levelt, Roelofs, \& Meyer, 1999) takes a strong position on the nature of these processing levels: There are only

This research was supported by the National Science Foundation (SBR 94-11627) and by the Edinburgh University Development Trust Research fund (EO8679). We acknowledge the help of Wendy Huinck and Marije van Zee with the scoring in Experiment 3 and Gabriella Vigliocco for many stimulating discussions that helped to shape some of the arguments presented here. Address correspondence to R. J. Hartsuiker, Department of Experimental Psychology, Ghent University, Henri Dunantlaan 2,9000 Ghent, Belgium (e-mail: robert.hartsuiker@ugent.be). top-down influences between levels. Therefore, grammatical encoding should not be affected by phonological information.

In this article, we examine whether there are morphophonological influences on grammatical processing. The domain of morphophonology is the phonological realization of morphemes. In different phonological and grammatical contexts, morphological elements may be realized differently even when they have the same meaning, as in the English past tense (e.g., looked ends in /t/ but lagged ends in $/ \mathrm{d} /$ ), and they may be realized in the same way even when their meanings differ (the plural of the noun rings, the third-person singular of the verb sings, and the possessive of the name Bing's are all /z/). The evidence for phonological influences on grammatical encoding in production is mixed, and observed effects appear to be small and fragile (e.g., Bock, 1986, 1987; Levelt \& Maassen, 1981). Given their theoretical importance, in the present research, our aim was to explore them in a different domain. Specifically, we report a line of evidence that focuses on the implementation of subject-verb agreement in speech.

\section{Subject-Verb Agreement}

Subject-verb number agreement is a prototypical example of "what syntax does" (Bock, 1995), and variations 
in the production of agreement offer a diagnostic tool for examining the forces at work in the implementation of this structural relation. One kind of variation involves the phenomenon of attraction. Attraction is a type of spurious agreement exhibited in such utterances as The time for fun and games are over, where the plural are agrees with games, rather than with the singular subject time. Attraction can be experimentally elicited by asking speakers to repeat and complete experimental preambles, such as

\section{The road to the mountains,}

where there is a mismatch in number between the head noun (road) and the local noun (mountains), and by comparing the number of agreement errors with a numbermatching control condition. When the mismatch involves a plural local noun, speakers show a tendency to produce a verb that agrees in number with the local noun, instead of with the head noun, counter to the descriptive and prescriptive patterns of English.

According to strictly top-down views of language production, the incidence of subject-verb agreement errors should not be influenced by the phonological realization of agreement morphology, because syntactic processes precede phonological processes. This claim was first investigated by Bock and Eberhard (1993) with comparisons of the completions of three types of visually presented items:

2. The ship for the crew [singular local noun],

3. The ship for the crews [plural local noun],

4. The ship for the cruise ["pseudoplural" local noun].

In Examples 2 and 3, the local noun is clearly specified as singular or plural, respectively. In Example 4, by contrast, the local noun (cruise) is singular, but it is homophonous with a true plural (Example 3). Agreement errors were more frequent after true plural local nouns (as in Example 3) than after controls with singular local nouns (as in Example 2). But the pseudoplurals (as in Example 4) attracted no more agreement errors than did the unambiguous controls. This is consistent with the hypothesis that subject-verb agreement is insensitive to the phonological aspects of the local noun.

Other studies suggest a different picture. Vigliocco, Butterworth, and Semenza (1995) reported evidence for a morphophonological effect on the occurrence of agreement errors in Italian. Most Italian nouns have a regular plural formation in which number is specified by the article and the suffix of the noun (e.g., la scoperta, the discovery-le scoperte, the discoveries). For a small group of nouns, though, number is specified only by the article, with the noun itself remaining invariant (e.g., la città, the city-le città, the cities), analogous to such English words as sheep (compare a sheep and some sheep). Sentence fragments with these number-invariant head nouns elicited more agreement errors than did fragments with unambiguous head nouns, especially in the conditions with singular head nouns and plural local nouns. Although there was no analogous effect of the morphophonology of the local noun, these data suggest that morphophonological specification of the head noun does influence agreement. Therefore, Vigliocco et al. (1995) suggested that grammatical encoding and morphophonological encoding interact.

Hartsuiker, Antón-Méndez, and van Zee (2001) used Dutch sentence fragments that ended with ambiguous or unambiguous direct object pronouns. With human antecedents, the plural direct object pronoun is hen. This pronominal form occurs only as a nonnominative plural, clearly specifying both number and case. In contrast, the plural pronoun for nonhuman antecedents is $z e$, which also serves as the nominative feminine singular and the nominative plural, making it ambiguous in both number and case. When these ambiguous pronouns ended the sentence fragment, more agreement errors occurred than when the pronoun was unambiguous. This suggests a morphophonological influence from the local pronoun.

Finally, Meyer and Bock (1999) assessed morphophonological effects on gender agreement between an antecedent and a pronoun in Dutch. Participants heard a preamble sentence containing an antecedent and a local noun (e.g., the Dutch equivalent of "Look, there is a horse [neuter gender] behind a fence [common gender]"), and subsequently they saw an adjective to be used in the completion (e.g., intelligent). The antecedent was identified by the meaning of the adjective (horses, but not fences, can be intelligent). The participants completed the preambles with a relative clause, which contained a gender-marked relative pronoun ("that [neuter] is intelligent"). According to prescriptive and descriptive patterns of Dutch, the pronoun and the antecedent should agree in gender. However, gender agreement errors occurred when the antecedent and the local noun mismatched in gender, and these errors were more frequent when the gender of the nouns was morphophonologically ambiguous. The ambiguity arose when indefinite determiners were used, because indefinite determiners are not gender specified and most Dutch nouns carry no reliable morphological cues as to their gender. Definite determiners, on the other hand, differ depending on the gender of the accompanying noun. This suggests that morphophonological factors also play a role in the computation of gender agreement.

In the present study, we investigated the role of morphophonological ambiguity in grammatical encoding in German and Dutch. We exploited two properties of these languages. The first was the German case system. In German, the case of a noun with a definite article is specified by both the definite article and the inflectional ending on the noun. Table 1 gives the inflectional paradigm for German nouns in the masculine, feminine, and neuter genders.

For present purposes, it is important to note that nominative and accusative forms are identical within the feminine and neuter genders. With respect to their morphophonology, an accusative singular is indistinguishable from a nominative singular, and an accusative plural from a nominative plural.

This ambiguity affects the morphology of nouns in prepositional phrases because, in German, the preposi- 
Table 1

Inflectional Paradigm for Masculine, Feminine, and Neuter German Nouns in the Nominative, Accusative, and Dative Cases

\begin{tabular}{|c|c|c|c|}
\hline \multirow[b]{2}{*}{ Case } & \multicolumn{3}{|c|}{ Noun Gender } \\
\hline & Masculine & Feminine & Neuter \\
\hline \multicolumn{4}{|c|}{ Singular } \\
\hline $\begin{array}{l}\text { Nominative } \\
\text { Accusative } \\
\text { Dative }\end{array}$ & $\begin{array}{l}\text { der Mann } \\
\text { den Mann } \\
\text { dem Mann }\end{array}$ & $\begin{array}{l}\text { die Frau } \\
\text { die Frau } \\
\text { der Frau }\end{array}$ & $\begin{array}{l}\text { das Kind } \\
\text { das Kind } \\
\text { dem Kind }\end{array}$ \\
\hline \multicolumn{4}{|c|}{ Plural } \\
\hline $\begin{array}{l}\text { Nominative } \\
\text { Accusative } \\
\text { Dative }\end{array}$ & $\begin{array}{l}\text { die Männer } \\
\text { die Männer } \\
\text { den Männern }\end{array}$ & $\begin{array}{l}\text { die Frauen } \\
\text { die Frauen } \\
\text { den Frauen }\end{array}$ & $\begin{array}{l}\text { die Kinder } \\
\text { die Kinder } \\
\text { den Kindern }\end{array}$ \\
\hline
\end{tabular}

Note-We have excluded the paradigm for the genitive case because its features do not affect the predictions for the experiments. We deviate from the usual order in which Germans cases are listed (i.e., nominative, genitive, dative, and accusative) for purposes of presentation.

tion controls whether the noun is accusative or dative. ${ }^{1}$ It is, therefore, possible to construct sentence preambles by using a local noun that is either unambiguous in case (dative local nouns) or ambiguous with the nominative (accusative local nouns). A set of examples is given below (Examples 5-8):

5. Die Stellungnahme zu der Demonstration [dative, singular local noun],

6. Die Stellungnahme zu den Demonstrationen [dative, plural local noun],

7. Die Stellungnahme gegen die Demonstration [accusative, singular local noun],

8. Die Stellungnahme gegen die Demonstrationen [accusative, plural local noun],

[Translation: The position on (5 and 6) / against (7 and 8) the demonstration/s.]

When the preposition requires the dative (Examples 5 and 6), the definite article of the local noun (der for feminine dative singular, dem for neuter dative singular, and den for dative plural) is different from the nominative (which requires the definite article die in feminine singular, das in neuter singular, and die for feminine and neuter nouns in plural). In contrast, when the preposition requires the accusative (Examples 7 and 8), a feminine or neuter local noun and its definite article are identical to the corresponding nominative, making the noun phrase ambiguous in case.

If the processes implementing subject-verb agreement are oblivious to morphophonology, there should be no difference in agreement between preambles with ambiguous versus unambiguous local nouns. Although we would expect more errors after plural than after singular local nouns in both conditions (the attraction effect), accusative and dative local nouns should behave similarly. If, however, the morphophonological identity of accusatives and nominatives influences agreement, we would expect more attraction for accusatives than for datives. In datives, the morphophonology of the local nouns, in conjunction with the morphophonology of their arti- cles, clearly specify them as something other than nominative, disqualifying them as subjects. But in accusatives, the local nouns and definite articles are always identical to the corresponding nominatives, making them potential subjects, at least superficially.

A related manipulation affected the morphophonological ambiguity of case in the head noun phrase. Although subject nouns are always nominative, the ambiguity of nominative case specification depends on gender (see Table 1). Subject nouns with feminine and neuter genders are ambiguous between nominative and accusative, whereas singular masculine subject nouns are clearly nominative. If the ambiguity of case in the head noun phrase results in confusion about which noun is the subject, one would expect more agreement errors with neuter and feminine head nouns in the singular than with masculine head nouns in the singular.

The second property important to the logic of the experiments is the ambiguity of number in singular definite determiners. In both German and Dutch, the form of the definite determiner depends on the gender of the corresponding noun. For nominative singular nouns in German, the determiner is die for feminine nouns, der for masculine nouns, and das for neuter nouns. The corresponding forms in the plural are all die. Thus, as far as the definite determiner is concerned, feminine nouns in the nominative case are ambiguous in number, and masculine and neuter nouns are unambiguously singular or plural. A similar situation holds in Dutch (irrespective of case, which is specified only for pronouns, as in English). Dutch has only two viable genders, common (which combines the now archaic masculine and feminine genders) and neuter. Common gender nouns take the determiner $d e$ (the) in both the singular and the plural; neuter gender nouns take the determiner het in the singular and $d e$ in the plural. Thus, for neuter nouns, the determiner's number is unambiguous, but for common gender nouns, the determiner's number is ambiguous. If the ambiguity of number in the head noun phrase interferes with agreement construction, one would expect German feminine head nouns to elicit more errors than do masculine or neuter nouns and one would expect Dutch common gender nouns to elicit more errors than do neuter nouns.

These predictions were tested in three experiments. Experiments 1 and 2 tested the predictions for German regarding ambiguity of case specification in the local noun phrase and in the head noun phrase. Experiment 3, in Dutch, tested the prediction about number ambiguity in a language without the potential for contamination from overt case specification.

\section{EXPERIMENT 1 German}

\section{Method}

Participants. Twenty adults with a median age of 52 years (range, 40-72 years) participated. They were members of a healthy control subject pool for aphasia research at the Max Planck Insti- 
tute for Psycholinguistics. All were native speakers of German and were paid for participation.

Materials. We constructed 32 critical items. Every item was a complex noun phrase, consisting of a definite article and a noun (the head noun) in the nominative singular, followed by a prepositional phrase that included a preposition and a noun phrase (the local noun phrase). Two different prepositions were used in different versions of each item, one preposition requiring the accusative case and one requiring the dative case. The orthogonal manipulation of local noun number (singular or plural) along with the preposition (requiring the accusative or the dative case) yielded four versions of each item, as in Examples 5-8. ${ }^{2}$ The local nouns had either feminine or neuter gender. When these local nouns followed a dative preposition (Examples 5 and 6), the local noun phrases were unambiguously different from the corresponding nominative form. But in the accusative (Examples 7 and 8), the local noun phrases were ambiguous between nominative and accusative, in both the singular and the plural versions.

A third experimental variable was case ambiguity of the head noun. Ambiguous and unambiguous conditions were created by varying the gender of the head noun. The determiner for masculine nouns in the nominative singular (der) is unambiguous. But the corresponding determiners for feminine and neuter nouns (die, das) are ambiguous between nominative and accusative singular (see Table 1). The unambiguous condition was represented by 15 items with masculine head nouns, and the ambiguous condition was represented by 17 items, 11 with feminine head nouns and 6 with neuter head nouns. The reason for the unequal numbers of items in these two conditions (15 and 17) was an oversight in material construction.

We ensured that the items in each gender condition did not differ with respect to other variables that might influence agreement-in particular, frequency and plausibility. The frequency of each head noun was taken from the CELEX database (Baayen, Piepenbrock, \& Van Rijn, 1993). There were no statistically reliable differences between the means of the logarithmically transformed frequencies (masculine, $M=1.43, S D=0.64$; feminine, $M=1.59, S D=0.64$; neuter, $M=1.92, S D=0.53$ ). Plausibility was tested by presenting the experimental materials to 16 raters, none of whom participated in the experiments. They were asked to rate the plausibility of each item on a 7-point scale, where a score of 7 meant plausible. There was no reliable difference between the genders (masculine, $M=5.68, S D=0.83$; feminine, $M=5.52, S D=0.84$; neuter, $M=$ $5.69, S D=0.83$ ), no effect of case or number of local noun, and no interaction between those variables and the gender of the head noun.

We constructed 56 filler preambles, 44 with plural head nouns and 12 with singular head nouns. Number of the head noun (which normally controls agreement) was, therefore, balanced in the complete set of critical and filler items: 44 singular and 44 plural. Fourteen of the fillers' head nouns were masculine, 18 feminine, and 24 neuter, so that gender of heads was nearly balanced in the complete list of critical and filler trials ( 29 masculine, 29 feminine, and 30 neuter). To lend diversity to the list, the fillers came in several constructionsthat is, simple noun phrases (article [+adjective] + noun) and complex noun phrases (noun phrases with embedded prepositional phrases or relative clauses).

A random list of the 32 critical items and the 56 fillers was assembled, with the restriction that 6 filler items began the list and any 2 critical items were separated by at least 1 filler item. Four variations of this list were created by systematically changing the version in which a given critical item appeared (accusative or dative preposition with a singular or a plural local noun). Only one version of each critical item occurred in each list variation, and 8 items represented each of the four conditions in each variation. Across the four list variations, all four versions of each critical item occurred just once. The resulting four experimental lists were tape recorded by a female native speaker of German.

Procedure. Each participant took part in four experimental sessions and received a different experimental list in each session. The order of administration of the experimental lists was varied, with 5 participants receiving each of four different orders. Sessions were separated by at least 1 week. The participants were instructed that they would hear the beginnings of sentences from a tape recorder and that their task was to repeat the fragment and to complete it immediately as a full sentence. The experimenter played one preamble at a time and then stopped the tape recorder while the participants repeated and completed the preamble. The whole session was tape recorded.

Scoring and data analysis. All of the tape recordings of the experimental sessions were transcribed and then checked by an independent judge. The judge listened to all of the tape recordings and corrected all transcription errors. Whenever the second judge was in doubt about the correctness of the transcription, the corresponding recordings were digitized and examined with the help of a speechediting system. In most cases, this yielded a clear decision about the response. When no decision was possible (in $0.7 \%$ of the responses), the response was categorized as miscellaneous. The remaining responses were assigned to one of three categories: (1) correct (the participant continued the preamble directly with a verb in the correct number), (2) subject-verb agreement error (a direct continuation with the wrong number on the verb), or (3) miscellaneous responses. This included incorrect repetitions of the preamble, utterances in which the preamble was not continued, and utterances containing additional words between the preamble and the verb.

\section{Results}

There were 2,446 correct responses, 53 agreement errors $(2.1 \%)$, and 61 miscellaneous responses. Agreement errors occurred more frequently in the case-unambiguous (dative) condition with plural local nouns (18) than in the case-unambiguous control condition (9) and more frequently in the case-ambiguous (accusative) condition with plural local nouns (24) than in the case-ambiguous control condition (2). This suggests that there was an attraction effect (more errors with plural local nouns than with singular local nouns) and that the attraction effect was larger in the case-ambiguous condition.

Table 2 reports the number of observations in each response category as a function of local noun number and local noun case separately for each of the three genders of the head nouns.

There were differences between the three genders of the head nouns: agreement errors occurred more frequently for feminine items $(5.1 \%)$ than for neuter $(0 \%)$ or masculine $(0.7 \%)$ head nouns. Evidently, the feminine head noun items were disproportionately responsible for the larger attraction effects that occurred when case was ambiguous. Therefore, we report separate statistical tests for each head noun gender, as well as analyses for the complete data set.

The statistical tests were performed with the proportion of agreement errors as the dependent variable. Two analyses of variance (ANOVAs) were conducted, one for participants $\left(F_{1}\right)$ and one for items $\left(F_{2}\right)$. The design for the analysis by participants included three orthogonal within-subjects factors: (1) the number of the local noun (singular or plural), (2) the case ambiguity of the local noun (ambiguous nominative/accusative or unambiguous dative), and (3) the case ambiguity of the head noun, either ambiguous nominative/accusative (i.e., feminine and neuter head nouns) or unambiguous nominative (i.e., 
Table 2

Experiment 1: Percentages of Correct Responses, Agreement Errors, and Miscellaneous Responses as a Function of Case Ambiguity in Local Noun Phrase, Number of Local Noun, and the Gender of Subject Noun

\begin{tabular}{lccc}
\hline \multicolumn{1}{c}{ Condition } & $\begin{array}{c}\text { Correct } \\
\text { Responses }\end{array}$ & $\begin{array}{c}\text { Agreement } \\
\text { Errors }\end{array}$ & $\begin{array}{c}\text { Miscellaneous } \\
\text { Responses }\end{array}$ \\
\hline \multicolumn{4}{c}{ Feminine Head Noun } \\
Case unambiguous (dative), singular & 93.6 & 4.1 & \\
Case unambiguous (dative), plural & 90.0 & 5.9 & 2.3 \\
Case ambiguous (accusative), singular & 96.8 & 0.9 & 2.3 \\
Case ambiguous (accusative), plural & 88.6 & 9.5 & 1.8 \\
$\quad$ Neuter Head Noun & & \\
Case unambiguous (dative), singular & 99.2 & 0.0 & 0.8 \\
Case unambiguous (dative), plural & 98.3 & 0.0 & 1.7 \\
Case ambiguous (accusative), singular & 97.5 & 0.0 & 2.5 \\
Case ambiguous (accusative), plural & 97.5 & 0.0 & 2.5 \\
$\quad \quad$ Masculine Head Noun & & \\
Case unambiguous (dative), singular & 98.3 & 0.0 & 1.7 \\
Case unambiguous (dative), plural & 97.7 & 1.7 & 0.7 \\
Case ambiguous (accusative), singular & 97.7 & 0.0 & 2.3 \\
Case ambiguous (accusative), plural & 94.0 & 1.0 & 5.0 \\
\hline
\end{tabular}

masculine head nouns). The item analysis treated the third factor between items and used unequal- $n$ ANOVAs, because of the imbalance in the number of items in each case-of-head-noun condition.

There were significant main effects of the number of the local noun $\left[F_{1}(1,19)=7.1, p<.05 ; F_{2}(1,30)=22.6\right.$, $p<.01]$ and the case ambiguity of the head noun $\left[F_{1}(1,19)=6.0, p<.05 ; F_{2}(1,30)=4.5, p<.05\right]$. The interaction between the number of the local noun and the ambiguity of the head noun was marginal in the participants analysis and significant in the items analysis $\left[F_{1}(1,19)=3.7, p=.07 ; F_{2}(1,30)=4.3, p<.05\right]$, and the three-way interaction between local noun number, case ambiguity of the local noun, and case ambiguity of the head noun was significant $\left[F_{1}(1,19)=7.9, p<.05\right.$; $\left.F_{2}(1,30)=5.2, p<.05\right]$. The interaction between the case ambiguity and the number of the local noun was marginally significant $\left[F_{1}(1,19)=3.6, p=.07 ; F_{2}(1,30)=\right.$ $2.8, p=.10]$. The main effect of the local noun's case ambiguity was clearly not significant $\left(F_{1}<1\right.$ and $\left.F_{2}<1\right)$. An analysis of the miscellaneous responses yielded no significant main effects or interactions.

A separate analysis for the items with feminine head nouns revealed a significant main effect of local noun number [singular or plural: $F_{1}(1,19)=5.9, p<.05$; $\left.F_{2}(1,10)=32.3, p<.0005\right]$ and, most important, a significant interaction between number of the local noun and case of the local noun phrase $\left[F_{1}(1,19)=6.7, p<\right.$ $\left..05 ; F_{2}(1,10)=6.7, p<.05\right]$, with errors occurring primarily when the local noun's case was morphophonologically ambiguous (i.e., accusative). The main effect of case of the local noun was not significant $\left(F_{1}<1\right.$ and $F_{2}<1$ ). Additional analyses showed that for local nouns in the ambiguous accusative case, significantly more agreement errors occurred after a plural local noun than after a singular local noun $\left[F_{1}(1,19)=8.8, p<.01\right.$; $\left.F_{2}(1,10)=6.3, p<.05\right]$. But for local nouns in the un- ambiguous dative case, the corresponding difference was not significant $\left(F_{1}<1, F_{2}(1,10)=2.2, p=.17\right]$. Separate analyses for items with neuter and masculine head nouns did not reveal any main effects or interactions.

\section{Discussion}

Experiment 1 replicated the usual effect of attraction on subject-verb number agreement: Items with a plural local noun elicited more agreement errors than did items with a singular local noun. We also found an effect of the case ambiguity of the head noun, a marginally significant interaction between the number of the local noun and the case ambiguity of the local noun, and a significant three-way interaction between number of the local noun, case ambiguity of the head noun, and case ambiguity of the local noun. To interpret this data pattern, it is important to consider the data separately for each gender.

First, agreement errors occurred almost exclusively with feminine head noun items. The neuter head noun items elicited no errors, and the masculine head noun items elicited very few errors. This suggests that the effect of case ambiguity of the head noun (i.e., feminine and neuter, as compared with masculine, head nouns) is really an effect of number ambiguity of the head noun's determiner. The determiner with neuter nouns (das) is unambiguously singular, but the determiner with feminine head nouns (die) is ambiguous between singular and plural. We will reconsider this morphophonological effect of number ambiguity in Experiment 3, testing Dutch, a language in which case and number are unconfounded.

Second and more critically, there was a significant interaction between case ambiguity in the local noun phrase and number of the local noun for items with feminine head nouns. This explains the significant three-way interaction and the marginal interaction between local noun case ambiguity and local noun number in the complete data set. 
These findings strongly suggest morphophonological effects on the production of subject-verb agreement. There appears to be an effect of number ambiguity of the subject noun's determiner (more agreement errors if it is ambiguous). Provided there are enough agreement errors, there also appears to be an effect of case ambiguity in the local noun phrase: The verb tends to agree with the local noun phrase, but only if the phonological form of that phrase is consistent with the nominative.

One way in which such effects could arise is if morphological ambiguities create comprehension problems, making the repetition and completion of the preambles more error prone. If true, there would not only be more agreement errors for ambiguously specified items, but also more failures of repetition and completion (classified as miscellaneous responses). Table 2 shows no support for this interpretation. The failures in repetition and completion were not systematically related to the number of agreement errors. In fact, the results for the miscellaneous responses were the reverse of what the comprehension hypothesis would predict.

In sum, Experiment 1 suggests that ambiguity of case in the local noun phrase and ambiguity of number in the subject noun phrase play a role in the computation of subject-verb agreement, whereas the ambiguity of case in the subject noun phrase does not. In Experiment 2, we replicated the effect of case in the local noun phrase.

\section{EXPERIMENT 2 German}

In Experiment 2, we tested only items with feminine heads - that is, heads whose determiner is number and case ambiguous. Because Experiment 1 showed that agreement errors were restricted mainly to these items, this allowed for a more sensitive evaluation of the effects from the local noun. We also tested younger adults, to exclude the possibility that the findings in Experiment 1 reflected something unique to language processing in elders. Experiment 2 also included a condition with plural subject nouns. Bock and Miller (1991) obtained an asymmetry in English such that attraction occurred primarily for local plural nouns after singular subjects. Including the plural subject condition in the present experiment allowed us to assess the cross-linguistic generality of that finding.

\section{Method}

Participants. Sixty-four native speakers of German, most of them students at the Free University Berlin (median age, 27 years), participated. They either were paid or received course credit.

Materials. There were 16 critical items, each one in eight versions. Every version was a complex noun phrase of the type used in Experiment 1. The eight versions resulted from the full crossing of three factors: (1) number of the head noun (singular or plural), (2) number of the local noun (singular or plural), and (3) case ambiguity of the local noun (ambiguous accusative or unambiguous dative). All the critical items had a feminine head noun with a feminine or neuter local noun. Eleven of the 16 critical items were the items with feminine head nouns from Experiment 1.
We constructed 112 filler items, 96 of which were simple noun phrases containing an article and a noun (48 items) or an article, an adjective, and a noun (48 items). The 16 remaining fillers were complex noun phrases containing an article and a noun, followed by a prepositional phrase that included a preposition and a noun phrase. Across all the critical and filler items, gender of head noun and number of head noun were completely balanced.

A random list of the critical and filler items was assembled, with the same restrictions as those that applied in Experiment 1. Eight variations of this list were created by systematically changing the version in which a given critical item appeared (i.e., head noun singular or plural, local noun singular or plural, or local noun ambiguous or unambiguous in case). Only one version of each critical item occurred in each list variation, and two items represented each of the eight conditions in each variation. Across the eight list variations, all eight versions of each critical item occurred just once. The resulting eight experimental lists were tape recorded by a female native speaker of German.

Procedure. Each of the eight list variations was presented to 8 of the 64 participants. Therefore, each participant received each item only once, and across all participants all the critical items contributed equally often to each of the eight experimental conditions. In all other respects, the procedure was the same as that in Experiment 1.

Scoring. Scoring and categorization of the responses were carried out in the same way as in Experiment 1.

\section{Results}

There were 910 correct responses, 63 agreement errors $(6.1 \%)$, and 51 miscellaneous responses. Table 3 reports the number of observations in the major response categories and the percentages of agreement errors per condition.

As in Experiment 1, all the statistical tests were performed using the proportion of agreement errors as the dependent variable. Both the by-participant and the byitem analyses included three orthogonal factors: (1) the number of the head noun (singular or plural), (2) the case ambiguity of the local noun (ambiguous between accusative and nominative or unambiguously dative), and (3) the match or mismatch of local noun and head noun with respect to number (head noun and local noun have the same or a different number).

The analyses revealed main effects of the number of the head noun $\left[F_{1}(1,63)=17.8, p<.005 ; F_{2}(1,15)=\right.$ $3.5, p=.08]$ and of number match $\left[F_{1}(1,63)=7.2, p<\right.$ $\left..01 ; F_{2}(1,15)=3.3, p=.09\right]$ that were significant in the analysis by participants but were marginal by items. The interaction between these two factors was significant $\left[F_{1}(1,63)=5.6, p<.05 ; F_{2}(1,15)=5.3, p<.05\right]$ and so was the three-way interaction between number of the head noun, number match, and case ambiguity of the local noun $\left[F_{1}(1,63)=6.7, p<.05 ; F_{2}(1,15)=5.3, p<\right.$ $.05]$. The latter interaction indicates that the attraction effect occurred reliably only in the condition with singular head nouns and case-ambiguous local nouns: The comparison of the plural local noun condition (21 errors) with the singular local noun control condition (6 errors) was significant $\left[F_{1}(1,63)=10.3, p<.005 ; F_{2}(1,15)=\right.$ 5.7, $p<.05]$. There was no attraction effect (all $F_{1} \mathrm{~s}<1$ and $F_{2} \mathrm{~s}<1$ ) in the conditions with singular head nouns 
Table 3

Experiment 2: Percentages of Correct Responses, Agreement Errors, and Miscellaneous Responses as a Function of Number of Head Noun, Case Ambiguity in Local Noun Phrase, and Number Match Between Head and Local Noun

\begin{tabular}{lccc}
\hline \multicolumn{1}{c}{ Condition } & $\begin{array}{c}\text { Correct } \\
\text { Responses }\end{array}$ & $\begin{array}{c}\text { Agreement } \\
\text { Errors }\end{array}$ & $\begin{array}{c}\text { Miscellaneous } \\
\text { Responses }\end{array}$ \\
\hline \multicolumn{4}{c}{ Singular Head Noun } \\
Case unambiguous (dative), match & 86.7 & 7.0 & \\
Case unambiguous (dative), mismatch & 85.2 & 10.2 & 4.3 \\
Case ambiguous (accusative), match & 91.4 & 4.7 & 3.9 \\
Case ambiguous (accusative), mismatch & 76.6 & 16.4 & 7.0 \\
$\quad$ Plural Head Noun & & \\
Case unambiguous (dative), match & 95.3 & 0.8 & 3.9 \\
Case unambiguous (dative), mismatch & 94.5 & 3.9 & 1.6 \\
Case ambiguous (accusative), match & 91.4 & 3.9 & 4.7 \\
Case ambiguous (accusative), mismatch & 89.8 & 2.3 & 7.8 \\
\hline
\end{tabular}

and case-unambiguous local nouns, plural head nouns with case-ambiguous local nouns, and plural head nouns with case-unambiguous local nouns.

\section{Discussion}

Experiment 2 confirmed the effect of case ambiguity obtained in Experiment 1. When local noun phrases were ambiguous between nominative or accusative, there was more attraction than when the local nouns were dative, with unambiguous case. We also replicated in German the asymmetry that Bock and Miller (1991) found in English: Attraction was restricted to conditions with singular head nouns.

\section{EXPERIMENT 3 Dutch}

In Experiment 3, we returned to the question of whether the ambiguity of the head noun's number alone influences agreement. We investigated this question in Dutch, where the definite determiner $d e$ is number ambiguous, whereas the definite determiner het is unambiguous. Het is the singular definite determiner for neuter gender nouns; $d e$ is the definite determiner for common gender singular nouns and for plural nouns of either gender. The advantage of testing in Dutch is that it has no case specifications on determiners and nouns: The determiner is always $d e$ for common gender nouns and het for neuter, singular nouns, regardless of their grammatical function. Therefore, unlike the results for German in Experiment 1, any differences between $d e$ words and het words as head nouns cannot be explained in terms of case ambiguity. Instead, number ambiguity is a more likely culprit.

\section{Method}

Participants. Seventy-two native speakers of Dutch, all undergraduate students at the University of Nijmegen, participated in the experiment. Their ages ranged from 17 to 33 years.

Materials. We constructed 32 Dutch preambles, each a complex noun phrase with an embedded prepositional phrase. There were eight versions resulting from the full crossing of three factors: (1) gender of the head noun (neuter or common), (2) number of the head noun (singular or plural), and (3) number of the local noun (singular or plural). The common and neuter head nouns for each item required the articles $d e$ and het, respectively; the local nouns always required the article $d e$. An example of the eight versions of an item is provided in 9-16.

9. Het plein bij de kerk [singular, neuter gender head noun, singular local noun],

10. Het plein bij de kerken [singular, neuter gender head noun, plural local noun],

11. De straat bij de kerk [singular, common gender head noun, singular local noun],

12. De straat bij de kerken [singular, common gender head noun, plural local noun],

13. De pleinen bij de kerk [plural, neuter gender head noun, singular local noun],

14. De pleinen bij de kerken [plural, neuter gender head noun, plural local noun],

15. De straten bij de kerk [plural, common gender head noun, singular local noun],

16. De straten bij de kerken [plural, common gender head noun, plural local noun],

[Translation: The square(s) (plein, pleinen) / street(s) (straat, straten) near the church(es).]

The singular head noun never ended with the letter combinations $s$, en, or je, because $s$ and en are common plural suffixes in Dutch (and the plural always requires the determiner $d e$ ) and je is the suffix for diminutives (which always require the determiner het). As in Experiment 1, the two head nouns for the neuter gender and common gender versions of an item were matched with respect to frequency (from CELEX) and plausibility. There was no difference between the means of the logarithmically transformed frequencies in the two conditions (de nouns, $M=1.37, S D=0.59$; het nouns, $M=1.38, S D=0.77$ ). Plausibility was assessed with the same procedure as that in Experiment 1, using 32 raters who did not participate in the experiment. There was no difference between the conditions in mean plausibility ( $d e$ condition, $M=5.57, S D=1.29$; het condition, $M=5.70, S D=1.27$ ). In a final pretest, 10 raters filled in the missing article of the head noun. Each head noun was unanimously rated as requiring either de or het.

We constructed 48 fillers. Half of the head nouns required the article het, and the other half required the article de. Sixteen filler 
items had the same syntactic structure as the experimental items. Half of these had a singular head noun, and half had a plural head noun. The remaining 32 filler items were simple noun phrases at least two words and at most four words long. Half of these items were singular, and half were plural. Thus, gender and number of the head noun were completely balanced across the complete set of critical and filler trials.

Each participant received a separately randomized list containing 32 experimental items and 48 filler items, with 4 items in each of the eight experimental conditions. Each list started and ended with eight filler items. The remaining items were distributed at random. Due to an error, not all the conditions were equally distributed over participants in the experiment, creating an imbalance in the design. Because of this, each participant received between 3 and 5 items in each condition, instead of exactly 4 . The total number of items presented in each condition is listed in the final column of Table 4.

Procedure. The participants were tested individually in sessions lasting about $15 \mathrm{~min}$. The experiment started with six practice items. If necessary, the participants could interrupt the task for extra instructions after these six items. The entire session was recorded on audio tape. The participants were instructed that they would see sentence fragments on a computer screen and that their task was to repeat the fragment out loud and complete it immediately as a full sentence. We stressed the importance of completing each sentence fragment before a deadline of 2,240 msec after the fragment's appearance. The approach of the deadline was indicated on the screen with a bar decreasing in length according to the time remaining.

The participants initiated each trial by pressing a button. Each trial started with a blank screen for $1,000 \mathrm{msec}$. Then a fixation point appeared in the center of the screen for $500 \mathrm{msec}$, followed by a blank screen for $250 \mathrm{msec}$. Subsequently the preamble appeared in the center of the screen for $800 \mathrm{msec}$. Between the disappearance of the preamble and the appearance of the deadline bar, $300 \mathrm{msec}$ expired. Time from disappearance of the preamble until the deadline signal was $1,140 \mathrm{msec}$. This procedure has been employed in previous studies (e.g., Hartsuiker et al., 2001; Vigliocco, Hartsuiker, Jarema, \& Kolk, 1996) with results comparable to those of other experiments in the literature. Because the 800 -msec presentation of the fragment allows too little time to read the fragment aloud from the screen, the repetition of the fragment relies on shortterm memory (as in auditory presentation) after the disappearance of the display.

Scoring. All the tape recordings were transcribed and scored. Two judges categorized the responses of the participants. When the opinions of the two judges did not agree, a third judge evaluated the categorizations and made a final, decisive judgment. The responses were assigned to scoring categories in the same way as in the previous experiments, with the addition that the trials in which the verb was produced after the deadline signal were treated as miscellaneous responses. ${ }^{3}$

\section{Results}

There were 1,489 correct responses, 32 agreement errors $(1.4 \%)$, and 783 miscellaneous responses. Table 4 reports the results for each experimental condition.

In the conditions with singular head nouns, agreement errors never occurred in the number-matching control conditions. The errors predominantly ( 20 of 21 errors) occurred when the determiner of the head noun was number ambiguous. Although the error rate overall was low, the error rate in the number-ambiguous condition (7.2\%) was comparable to error rates observed in earlier studies in Dutch with comparable items (e.g., Vigliocco et al., 1996). In the conditions with plural head nouns, there were few errors, and there was no evidence of an attraction effect.

Because there were no agreement errors in the control conditions with singular subjects and singular local nouns, we excluded these conditions from analysis. To maintain a symmetrical design, we also excluded the two control conditions with plural subjects and plural local nouns from initial analysis. Two ANOVAs were carried out. The dependent variable in all analyses was the proportion of agreement errors in the number mismatch conditions. Both the by-participants and by-items analyses included two orthogonal factors: (1) the number of the head noun (singular or plural) and (2) the number ambiguity of the head noun's determiner.

The analyses revealed main effects of the head noun's number $\left[F_{1}(1,71)=8.3, p<.005 ; F_{2}(1,28)=7.0, p<\right.$ $.02]$ and of the determiner's number ambiguity $\left[F_{1}(1,71)=\right.$ $\left.16.1, p<.0005 ; F_{2}(1,28)=9.6, p<.005\right]$. The interaction between these two factors was also significant

Table 4

Experiment 3: Percentages of Correct Responses, Agreement Errors, and Miscellaneous Responses as a Function of Number of Head Noun, Number Ambiguity of Determiner of Head Noun, and Number Match Between Head and Local Noun

\begin{tabular}{|c|c|c|c|c|}
\hline Condition & $\begin{array}{c}\text { Correct } \\
\text { Responses }\end{array}$ & $\begin{array}{c}\text { Agreement } \\
\text { Errors }\end{array}$ & $\begin{array}{c}\text { Miscellaneous } \\
\text { Responses }\end{array}$ & $N$ \\
\hline \multicolumn{5}{|c|}{ Singular Head Noun } \\
\hline Neuter (number unambiguous), match & 72.0 & 0.0 & 28.0 & 289 \\
\hline Neuter (number unambiguous), mismatch & 66.0 & 0.3 & 33.7 & 288 \\
\hline Common (number ambiguous), match & 75.0 & 0.0 & 25.0 & 296 \\
\hline Common (number ambiguous), mismatch & 55.4 & 7.2 & 37.4 & 278 \\
\hline \multicolumn{5}{|c|}{ Plural Head Noun } \\
\hline Neuter, match & 60.3 & 0.3 & 39.3 & 305 \\
\hline Neuter, mismatch & 68.1 & 0.7 & 31.1 & 270 \\
\hline Common, match & 58.3 & 1.3 & 40.4 & 314 \\
\hline Common, mismatch & 62.1 & 1.5 & 36.4 & 264 \\
\hline
\end{tabular}

Note-In singular neuter gender NPs, the definite determiner is het (number unambiguous); in singular common gender NPs and in plural NPs in Dutch, the definite determiner is de (number ambiguous). $N$ denotes the number of observations in each condition. 
$\left[F_{1}(1,71)=11.0, p<.005 ; F_{2}(1,28)=9.8, p<.005\right]$, reflecting the absence of a difference in errors when the head noun was plural $\left(F_{1}<1\right.$ and $\left.F_{2}<1\right)$. With singular head nouns, the ambiguous ( $d e$ ) and the unambiguous (het) conditions were significantly different $\left[F_{1}(1,71)=\right.$ $\left.17.9, p<.0005 ; F_{2}(1,28)=12.6, p<.001\right]$.

Although there were no agreement errors in the baseline conditions with singular head nouns, agreement errors were observed in the baseline conditions with plural head nouns. Therefore, we ran separate analyses for the plural head noun conditions. These analyses included two orthogonal variables: gender of the head noun (common or neuter) and number of the local noun (singular or plural). These analyses yielded no significant effect for gender of the head noun $\left[F_{1}(1,71)=2.5, p=.117\right.$; $\left.F_{2}(1,28)=1.44, p=.240\right]$, no effect for number of the local noun $\left(F_{1}<1\right.$ and $\left.F_{2}<1\right)$, and no interaction between the two factors $\left(F_{1}<1\right.$ and $\left.F_{2}<1\right)$.

Because there were many more miscellaneous responses than in Experiments 1 and 2, we performed additional analyses on this category of response. In $21 \%$ of the miscellaneous responses, the response was produced after the deadline (see note 3 ). In $37 \%$, correctness of agreement could not be determined, either because the head noun or the verb was not produced or could not be reliably transcribed or because the sentence had a structure in which the preamble was an object. In $42 \%$, the preamble was misreported, or the number of the local noun could not be reliably transcribed. Only the latter category varied with experimental condition: Repetition errors occurred significantly more often when the local noun was plural $\left[F_{1}(1,71)=16.9 ; F_{2}(1,28)=16.6\right]$, independently of whether the numbers of head and local nouns matched or mismatched. ${ }^{4}$ None of these categories of miscellaneous responses was systematically related to the number of agreement errors (see the Discussion section in Experiment 1).

\section{Discussion}

Experiment 3 clearly revealed attraction effects with singular subjects and no attraction with plural subjects, in accord with the findings from German in Experiment 2, from English in Bock and Miller (1991), from French in Fayol, Largy, and Lemaire (1994), and from Spanish in Vigliocco, Butterworth, and Garrett (1996). The key result was that agreement errors were restricted to preambles with subject noun phrases in which the definite determiner was morphophonologically ambiguous for number - that is, the items requiring the article $d e$ in the singular. Thus, the effect of the number specification of the definite determiner in the head noun phrase, suggested by the results of Experiment 1, was confirmed in a language that allowed us to examine number ambiguity independently of case ambiguity.

\section{GENERAL DISCUSSION}

The present experiments establish effects of morphophonological ambiguity on the construction of subject- verb agreement in two different languages and with two different kinds of morphosyntactic information carrying number specifications. First, we showed in German that there was more attraction in items with case-ambiguous (accusative) local nouns than with case-unambiguous (dative) local nouns. The case specifications of the accusative local nouns, in contrast to the datives, were indistinguishable from the case specifications of nominative nouns, which usually control agreement.

Second, we showed in both German and Dutch that there is an influence of morphophonological ambiguity in the head noun phrase (specifically, for the definite determiner of the head noun) but that not all ambiguities are equally important. Experiment 1 suggested that an ambiguity in case for subject nouns (comparing ambiguous nominative/accusative with unambiguous nominative) does not interfere with agreement construction. However, an ambiguity of number in the head noun phrase influenced agreement construction. So, in German, there was a much higher proportion of agreement errors for items with feminine nouns (which have numberambiguous determiners) than for items with masculine or neuter nouns (which have number-unambiguous determiners). This was confirmed in Experiment 3, which tested an analogous contrast without any possible confounding from case. Using Dutch materials, we again found more agreement errors for items with a numberambiguous determiner than for items with a numberunambiguous determiner.

The effects of morphophonological ambiguity corroborated the results from other reports. There is evidence for morphophonological effects of two kinds. One kind involves number in the subject noun phrase. In Vigliocco et al. (1995), determiners were unambiguously specified for number, and the number ambiguity of the noun itself was varied. The present study presents the reverse situation: Nouns were unambiguously specified for number, and the number ambiguity of the determiner was varied. The second kind of morphophonological effect involves ambiguity of case in the local noun phrase, either on a pronoun (Hartsuiker et al., 2001) or on the determiner, as in the present study.

Unambiguous morphophonology of such features as number and case apparently helps to ensure consistency in production, but there appear to be two distinct ways in which this occurs. First, unambiguous case in the local noun phrase ensures that the local noun cannot compete with the subject for control of number agreement. Note that the reverse did not occur: It did not seem to matter whether the subject was unambiguously specified for case. Second, ambiguity of number in the subject noun phrase influences the probability that mistakes will be made, either in assigning number features to the subject or in using that number information to determine the number of the verb.

In sum, we have provided evidence for morphophonological influences on subject-verb agreement. This clearly challenges the view that there are only top-down influences on grammatical encoding. In other words, in- 
teractive mechanisms must be at work during language production to allow information that is normally encoded later to affect earlier events. In the next section, we will consider three candidate mechanisms. We warn the reader beforehand that, in our view, it is presently not possible to distinguish among these mechanisms, on either logical or empirical grounds.

\section{Mechanisms of Interaction}

The first and most familiar mechanism of interaction assumes that information feeds backward as well as forward in language production, in accord with theories such as those proposed by Dell (1986) and Stemberger (1985). Although neither of these theories is directly concerned with grammatical encoding, the potential involvement of the mental lexicon in implementing agreement brings such theories into play. In particular, if we assume feedback connections between word forms and lemma-based codes for morphosyntactic features that are compatible with them, it follows that ambiguously specified word forms will activate both incorrect and correct feature codes.

A second mechanism maintains the assumption of feedforward-only processes but assumes that a proportion of the errors is filtered out before articulation by way of a speech-monitoring system, in accord with theories of monitoring, such as that proposed by Levelt (1983, 1989; see also Hartsuiker \& Kolk, 2001). If the self-monitor can filter out syntactic errors before articulation and if the probability of filtering is higher for unambiguously specified phrases, our results would also follow.

A third account assumes that the effects arise when morphemes are integrated with structural frames for phrases. If both morphemes and frames carry specifications of syntactic features (e.g., Alario \& Caramazza, 2002; Bock, Eberhard, Cutting, Meyer, \& Schriefers, 2001; Lapointe \& Dell, 1989), ambiguously specified morphemes exert fewer constraints on their phrasal frames than do unambiguously specified morphemes. This allows errors to arise with ambiguous morphemes that would otherwise be thwarted by mismatching feature specifications. It is possible that conflicts arise at this stage (e.g., the morpheme bears accusative and nominative specifications, and the frame bears only accusative specification). It is conceivable that the resolution of this conflict can sometimes derail, forcing a spurious feature into the frame.

Clearly, our data do not discriminate among these alternatives. But this situation is hardly unique to the interface between syntax and morphophonology in language production. Vigliocco and Hartsuiker (2002) reviewed the interactivity question for several interfaces between processing levels in language production and concluded that current evidence does not allow distinguishing between direct feedback accounts and self-monitoring accounts. This situation holds, for example, for the lexical bias effect, the phenomenon in which phonological speech er- rors result, more often than chance would predict, in real words (e.g., Baars, Motley, \& MacKay, 1975; Dell, 1986; Dell \& Reich, 1981; Humphreys \& Swendsen, in press). It has not yet been possible to decide definitively between feedback and monitoring explanations of lexical bias, although considerable progress has been made in developing the competing theoretical frameworks within which these options are implemented. But a crucial first step was to establish the existence of the bias.

The present study establishes another apparent case of interactivity in language production. Although it may be some time before enough is known about the mechanisms of sentence formulation to unequivocally explain how these effects arise, our results appear to demand that an adequate theory of grammatical encoding encompass an account of how morphophonological ambiguity influences agreement.

\section{REFERENCES}

Alario, F.-X., \& Caramazza, A. (2002). The production of determiners: Evidence from French. Cognition, 82, 179-223.

BaArs, B. J., Motley, M. T., \& MacKay, D. G. (1975). Output editing for lexical status in artificially elicited slips of the tongue. Journal of Verbal Learning \& Verbal Behavior, 14, 382-391.

BaAyen, R. H., Piepenbrock, R., \& Van Rijn, H. (1993). The CELEX lexical database. Philadelphia: Linguistic Data Consortium.

Bock, J. K. (1986). Meaning, sound, and syntax: Lexical priming in sentence production. Journal of Experimental Psychology: Learning, Memory, \& Cognition, 12, 575-586.

Bock, J. K. (1987). An effect of the accessibility of word forms on sentence structures. Journal of Memory \& Language, 26, 119-137.

Bock, J. K. (1995). Producing agreement. Current Directions in Psychological Science, 4, 56-61.

Bock, J. K., \& Eberhard, K. M. (1993). Meaning, sound, and syntax in English number agreement. Language \& Cognitive Processes, 8 , 57-99.

Bock, J. K., Eberhard, K. M., Cutting, J. C., Meyer, A. S., \& Schriefers, H. J. (2001). Some attractions of verb agreement. Cognitive Psychology, 43, 83-128.

Bock, J. K., \& LeVELT, W. J. (1994). Language production: Grammatical encoding. In M. A. Gernsbacher (Ed.), Handbook of psycholinguistics (pp. 945-984). San Diego: Academic Press.

Bock, J. K., \& Miller, C. A. (1991). Broken agreement. Cognitive Psychology, 23, 45-93.

DELL, G. S. (1986). A spreading-activation theory of retrieval in sentence production. Psychological Review, 93, 283-321.

Dell, G. S., \& REICH, P. A. (1981). Stages in sentence production: An analysis of speech error data. Journal of Verbal Learning \& Verbal Behavior, 20, 611-629.

Fay ol, M., LARgy, P., \& Lemaire, P. (1994). Cognitive overload and orthographic errors: When cognitive overload enhances subject-verb agreement errors. A study in French written language. Quarterly Journal of Experimental Psychology, 47A, 437-464.

Hartsuiker, R. J., Antón-MÉndez, I., \& VAn ZEe, M. (2001). Object attraction in subject-verb agreement construction. Journal of Memory \& Language, 45, 546-572.

Hartsuiker, R. J., \& Kolk, H. H. J. (2001). Error monitoring in speech production: A computational test of the perceptual loop theory. Cognitive Psychology, 42, 113-157.

Humphreys, K. R., \& SWEndsen, A. K. (in press). Lexical bias in speech errors: Evidence for feedback in spoken word production. Journal of Memory \& Language.

Lapointe, S. G., \& Dell, G. S. (1989). A synthesis of some recent work in sentence production. In G. N. Carlson \& M. K. Tanenhaus (Eds.), Linguistic structure in language processing (pp. 107-156). Dordrecht: Kluwer. 
Levelt, W. J. M. (1983). Monitoring and self-repair in speech. Cognition, 14, 41-104.

Levelt, W. J. M. (1989). Speaking: From intention to articulation. Cambridge, MA: MIT Press.

Levelt, W. J. M., \& MaAssen, B. (1981). Lexical search and order of mention in sentence production. In W. Klein \& W. [J. M.] Levelt (Eds.), Crossing the boundaries in linguistics: Studies presented to Manfred Bierwisch (pp. 221-252). Dordrecht: Reidel.

Levelt, W. J. M., Roelofs, A. \& Meyer, A. S. (1999). A theory of lexical access in speech production. Behavioral \& Brain Sciences, 22, 175 .

Meyer, A. S., \& Bock, J. K. (1999). Representations and processes in the production of pronouns: Some perspectives from Dutch. Journal of Memory \& Language, 41, 281-301.

Stemberger, J. P. (1985). An interactive activation model of language production. In A. W. Ellis (Ed.), Progress in the psychology of language (Vol. 1, pp. 143-186). London: Erlbaum.

Vigliocco, G., Butterworth, B., \& Garrett, M. F. (1996). Subjectverb agreement in Spanish and English: Differences in the role of conceptual constraints. Cognition, 61, 261-298.

Vigliocco, G., Butterworth, B., \& Semenza, C. (1995). Constructing subject-verb agreement in speech: The role of semantic and morphological factors. Journal of Memory \& Language, 34, 186-215.

Vigliocco, G., \& Hartsuiker, R. J. (2002). The interplay of meaning, sound, and syntax in sentence production. Psychological Bulletin, 128, $442-472$.

Vigliocco, G., Hartsuiker, R. J., Jarema, G., \& Kolk, H. H. J.
(1996). One or more labels on the bottles? Notional concord in Dutch and French. Language \& Cognitive Processes, 11, 407-442.

\section{NOTES}

1. For some German prepositions (e.g., in and an), the dative or the accusative case also depends on the thematic role of the subsequent noun (goal or location). Furthermore, some prepositions demand the genitive case (e.g., wegen des Mannes [because of the man] ). However, the use of the genitive after these prepositions appears to have vanished in contemporary colloquial German.

2. The complete set of items is available at the following Internet address: http://allserv.ugent.be/ rhartsui/materials.html\#HSBK.

3. A supplementary analysis, which included agreement errors on verbs produced after the deadline, yielded virtually identical results to the analysis that excluded these errors.

4. A further subdivision of responses revealed that this pattern is likely a result of our conservative transcription strategy. Repetition errors were particularly likely when both nouns were plural and the local noun ended with the plural suffix $-s$, which in Dutch is realized as the phoneme /s/. The plural of to be, zijn (are), begins with the phoneme/z/. Because of the phonological similarity between /s/ and /z/, the transcriber often had difficulty in detecting whether the suffix $-s$ was present and scored a response as miscellaneous whenever in doubt.

(Manuscript received December 19, 2000; revision accepted for publication August 5, 2003.) 